\title{
GASTRIC OUTLET OBSTRUCTION IN PROTON PUMP INHIBITOR ERA: A PROSPECTIVE STUDY OF FIFTY CASES IN TERTIARY HOSPITAL IN SOUTH INDIA
}

\author{
N. Suresh Kumar1, R. Jaivinod Kumar², Anand Murugan ${ }^{3}$ \\ ${ }^{1}$ Associate Professor, Department of Surgery, SRM Medical College Hospital and Research Centre, Kattankulathur, Chennai. \\ ${ }^{2}$ Associate Professor, Department of Surgery, SRM Medical College Hospital and Research Centre, Kattankulathur, Chennai. \\ ${ }^{3}$ Post Graduate, Department of Surgery, SRM Medical College Hospital and Research Centre, Kattankulathur, Chennai.
}

\section{ABSTRACT}

\section{BACKGROUND}

Gastric Outlet Obstruction implies complete or incomplete obstruction of the distal stomach pylorus or proximal duodenum.(1) Gastric outlet obstruction poses diagnostic and therapeutic challenges to general surgeons practicing in resource-limited countries. There is no sufficient data on this subject in our setting. Studies throughout the world shows drastic reduction in peptic ulcer disease (PUD) after Proton Pump Inhibitor (PPI) era.(1) This study was undertaken to highlight the etiology and treatment of Duodenal Ulcer (DU) and its most important complication, gastric outlet obstruction in Tertiary Hospital in South India. This study was done in SRM Medical College Hospital and Research Centre, Chennai, where in for all Gastric Ulcer (GU) and Duodenal Ulcer (DU) patients, eradication of H. Pylori has become a standard treatment. Surgical treatment is required for complications of peptic ulcer disease.(1) The aim of the study are two: first to analyze sex and age distribution of GU and DU and second to study the various types of management.

\section{MATERIALS AND METHODS}

This study on PUD and Gastric Outlet Obstruction (GOO) is based on a study of 50 cases that were admitted in SRM Medical College Hospital and Research Centre during the period of October 2014 to September 2015. The patients were evaluated by routine investigations like upper gastrointestinal endoscopy and ultrasonography of the abdomen. Barium meal and CECT abdomen in selected cases. All cases were taken up for curative/palliative surgery and operated depending upon the causes. All patients with a clinical diagnosis of gastric outlet obstruction were included after informed consent for the study, consecutively enrolled into the study. Statistical data analysis was done using SPSS computer software version 17.0.

\section{RESULTS}

In 37 cases, carcinoma of antrum with gastric outlet obstruction was found. Males are $25(68 \%)$ and females are 12 in numbers $(32 \%)$. In 12 cases of chronic duodenal ulcer with gastric outlet obstruction, males are 8 in number (67\%) and females are 4 in numbers (33\%). A total of 184 patients were studied and only 50 were included for the study. More than two-third of patients were males. Patients with malignant gastric outlet obstruction were older than those of benign type. This difference was statistically significant $(\mathrm{p}<0.001)$. Gastric cancer was the commonest malignant cause of gastric outlet obstruction, whereas peptic ulcer disease was the commonest benign cause. Commonest age group for cancer antrum with gastric outlet obstruction is 51-60 years and that of chronic DU with gastric outlet obstruction is 41-50 years. For antral carcinoma, Subtotal gastrectomy with Billroth II anastomosis was done for operable patients. Palliative anterior gastrojejunostomy for inoperable patients. For chronic DU, Truncal vagotomy with short loop posterior gastrojejunostomy was done in 12 patients.

\section{CONCLUSION}

So with the advent of recent antiulcer drugs the commonest cause of gastric outlet obstruction is carcinoma antrum of stomach, which has compared well with other center studies. Commonest age group for carcinoma antrum with gastric outlet obstruction is 51-60 years and that of chronic DU with gastric outlet obstruction is 41-50 years. Gastric outlet obstruction in our setting is more prevalent in males and the cause is mostly malignant. The majority of patients present late with poor general condition. Early recognition of the diagnosis, aggressive resuscitation and early institution of surgical management is of paramount importance if morbidity and mortality associated with gastric outlet obstruction are to be avoided.

\section{KEYWORDS}

Gastric Outlet Obstruction, Aetiology, Gastric Carcinoma, Peptic Ulcer.

HOW TO CITE THIS ARTICLE: Kumar NS, Kumar RJ, Murugan A. Gastric outlet obstruction in proton pump inhibitor era: a prospective study of fifty cases in tertiary hospital in South India. J Evolution Med Dent Sci 2016;5(6):305-308, DOI: $10.14260 /$ jemds/2016/66

Financial or Other, Competing Interest: None.

Submission 09-12-2015, Peer Review 10-12-2015,

Acceptance 02-01-2016, Published 19-01-2016.

Corresponding Author:

Dr. N. Suresh Kumar,

Associate Professor,

Department of Surgery,

SRM Medical College Hospital and Research Centre,

Kattankulathur,

Chennai-603203.

E-mail: nagansuresh@gmail.com

DOI: $10.14260 /$ jemds/2016/66

\section{INTRODUCTION}

Gastric outlet obstruction is one of the most common problem encountered in General Surgery. Gastric outlet obstruction poses diagnostic and therapeutic challenges to general surgeons practicing in resource-limited countries and contributes significantly to high morbidity and mortality.(2) The causes behind this common problem has changed, comparing with the incidence in the past. In this study on the gastric outlet obstruction, the various aspects and management of the gastric outlet obstruction, are analysed. 
In this study, main focus is on the two most common causes of gastric outlet obstruction and their management in the SRM Medical College Hospital and Research Centre.

\section{AIM OF THE STUDY}

1. To study the etiological causes of gastric outlet obstruction in adults getting admitted in SRM Medical College Hospital and Research Centre.

2. To study sex and age distribution in each of the causes.

3. To study the various types of management.

4. To find the most commonly performed surgeries for the two most common causes (CA antrum and cicatrized duodenal ulcer).

\section{MATERIAL AND METHODS}

This study on gastric outlet obstruction is based on a study of 50 cases that were admitted in SRM Medical College Hospital and Research Centre during the period of October 2013 to September 2014.

\section{Patient Selection}

\section{Inclusion Criteria}

1. Peptic ulcer disease.

2. Carcinoma pyloric antrum.

\section{Exclusion Criteria}

1. Pyloric or prepyloric atresia, mucosal diaphragm.

2. Duodenal atresia and stenosis.

3. Foreign bodies, bezoars and worms.

4. Infantile HPS.

5. Gastroduodenal tuberculosis.

6. Benign neoplasm of the stomach.

7. CA. Stomach with liver metastasis, ascites, peritoneal implantation.

The patients were investigated by routine investigations like upper gastrointestinal endoscopy, ultrasonography of the abdomen, barium meal and CT abdomen in selected cases. All cases were taken up for curative/palliative surgery and operated depending upon the causes.

\section{INVESTIGATIONS DONE}

Baseline investigations were done for all the patients; 22 cases had clinical pallor and their hemoglobin was below $10 \mathrm{gm} \%$. Complete blood chemistry including renal parameters and electrolytes were done.

LFT was done in all patients. One patient had jaundice and had serum bilirubin greater than $7 \mathrm{mg} \%$. No diabetic patient was found in this group. All patients had X-ray chest PA view, abdomen and ECG done. Endoscopy was done for all patients; 12 patients had fibrotic scarred duodenum and 37 patients had a growth in stomach mainly involving the antrum. One patient had duodenal narrowing due to extraneous compression.

Barium meal pictures were taken for cases with pyloric stenosis due to peptic ulcer disease and all 12 had dilated stomach and stasis of barium. Ultrasonogram was taken for all cases, no liver secondaries found. One case was detected to have celiac node. Two cases were detected to have ascites in ultrasonogram.

CECT scan abdomen was done for all malignant cases for staging workup. Blood grouping was done for all patients. Dehydration was corrected for all patients.
All patients on the pre-operative day underwent stomach lavage through Ryle's tube. Serum electrolytes were taken on the day of surgery for intravenous management intraoperatively.

\section{DISCUSSION}

After completing all investigations of the 50 cases the cause were found to be as follows.

\section{Distribution of Causes of Gastric Outlet Obstruction}

\begin{tabular}{|c|c|}
\hline Causes & Number of Cases \\
\hline Carcinoma of the antrum & 37 \\
\hline Chronic duodenal ulcer & 12 \\
\hline Other causes & 1 \\
\hline Total & $\mathbf{5 0}$ \\
\hline
\end{tabular}

\section{Gastric Outlet Obstruction Due to Antral Carcinoma}

\section{AGE DISTRIBUTION}

\begin{tabular}{|c|c|}
\hline Age & Number of Cases \\
\hline $21-30$ & 0 \\
\hline $31-40$ & 3 \\
\hline $41-50$ & 9 \\
\hline $51-60$ & 15 \\
\hline $61-70$ & 8 \\
\hline $71-80$ & 2 \\
\hline Total & $\mathbf{3 7}$ \\
\hline
\end{tabular}

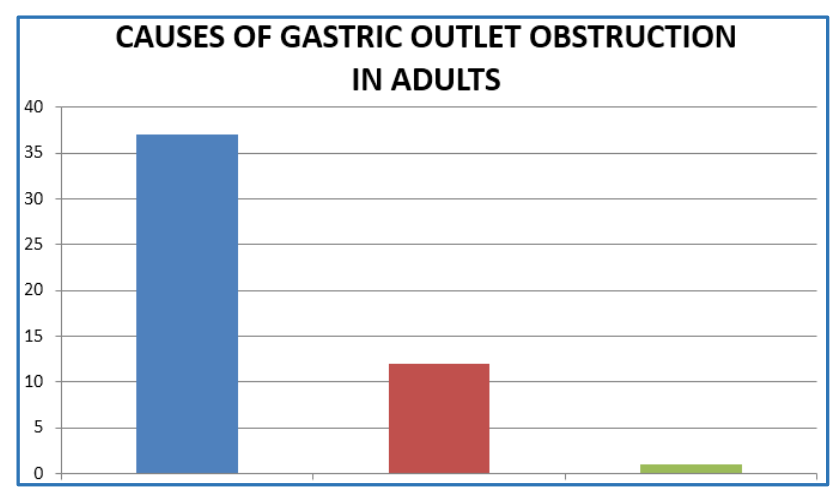

Age Distribution of Antral Carcinoma

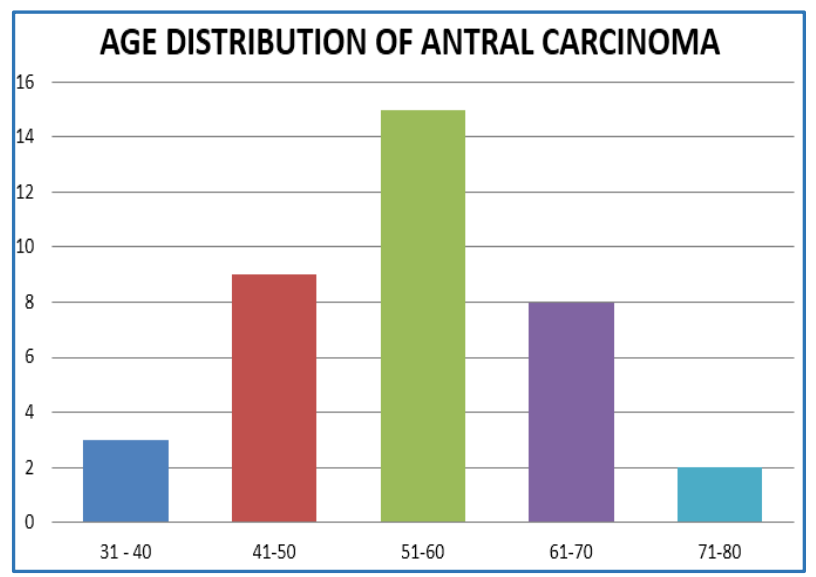

Age of Occurrence

Lowest (Age of occurrence) 36 years Highest (Age of occurrence) 75 years Commonest Age group 51 to 60 years 
Sex Distribution of CA Antrum

\begin{tabular}{|c|c|}
\hline Sex & No. of Patients \\
\hline Male & 38 \\
\hline Female & 12 \\
\hline Total & $\mathbf{5 0}$ \\
\hline
\end{tabular}

Sex Distribution in Antral Carcinoma

Male: $68 \%$

Female: $32 \%$

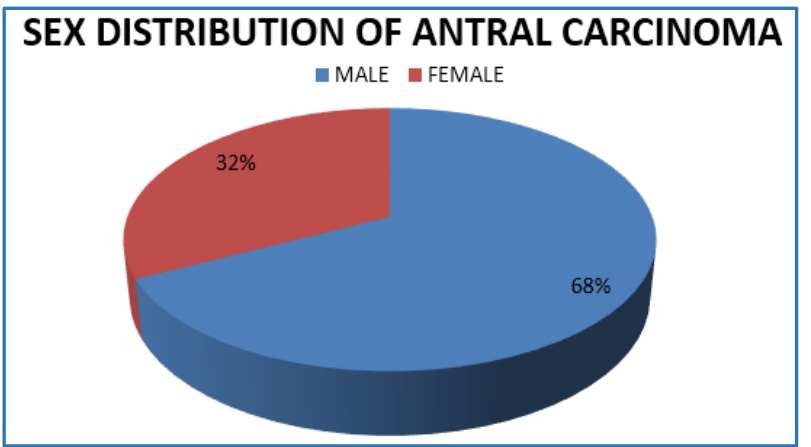

In this study, the incidence of carcinoma of antrum presenting with gastric outlet obstruction is high in males than females. It corresponds well with the earlier studies. The commonest age group of occurrence of malignancy was 51-60 years. The main complaints were epigastric dyspepsia and vomiting.

Gastric Outlet Obstruction Due to Cicatrized Duodenal Ulcer

Age Distribution of Cicatrized Duodenal Ulcer

\begin{tabular}{|c|c|}
\hline Age Group (In years) & Number of Cases \\
\hline $21-30$ & 2 \\
\hline $31-40$ & 2 \\
\hline $41-50$ & 4 \\
\hline $51-60$ & 2 \\
\hline $61-70$ & 2 \\
\hline Total & $\mathbf{1 2}$ \\
\hline
\end{tabular}

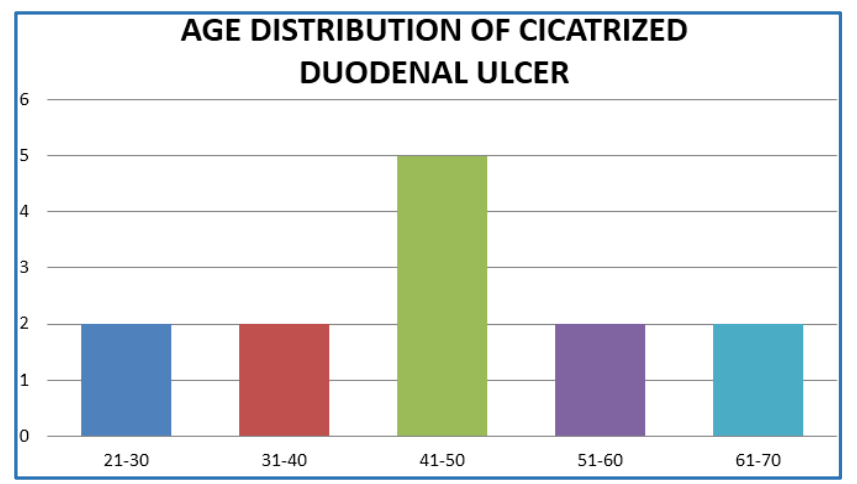

Age of Occurrence

Highest (Age of occurrence): 69 Years

Lowest (Age of occurrence): 28 Years

Commonest age of group: 41-50 Years

Percentage:

Male: $67 \%$

Female: $33 \%$

\section{SEX DISTRIBUTION OF CICATRIZED} DUODENAL ULCER

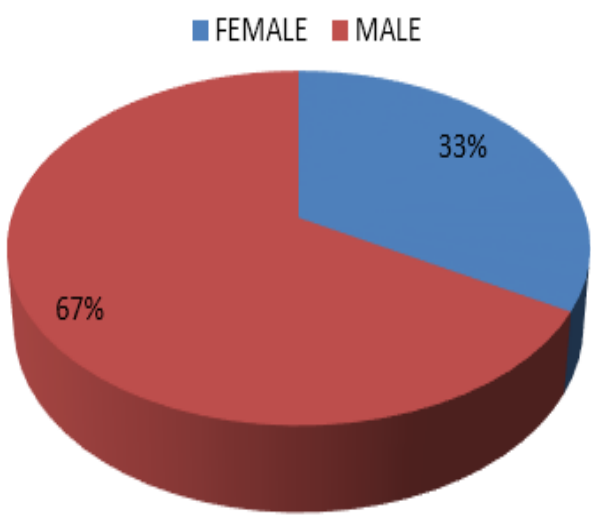

The predominance of males compared well with earlier studies. ${ }^{(3,4)}$ It also corresponds with fact that duodenal ulcer occurs more frequently in men than women due to various factors. Main complaints were vomiting and epigastric pain.

\section{TREATMENT}

Patients with Antral Cancer and Gastric Outlet Obstruction

\begin{tabular}{|c|c|}
\hline Sex & No. of Cases \\
\hline Male & 25 \\
\hline Female & 12 \\
\hline Total & $\mathbf{3 7}$ \\
\hline
\end{tabular}

- $\quad$ All patients were posted for laparotomy.

- General anesthesia was given for all patients. All cases were operated through midline incision.

- On Laparotomy.

a. Ascites: 2 patients.

b. Fixity to adjacent structures: 1 patient.

c. Liver secondaries: Nil.

- Subtotal gastrectomy with Billroth II anastomosis was done for operable patients. Palliative anterior gastrojejunostomy for inoperable patients.

Patient with Chronic DU and Gastric Outlet Obstruction

\begin{tabular}{|c|c|}
\hline SEX & NUMBER OF CASES \\
\hline MALES & 9 \\
\hline FEMALES & 3 \\
\hline TOTAL & $\mathbf{1 2}$ \\
\hline
\end{tabular}

- General anaesthesia was given for all patients, through midline incision abdomen was opened.

- Truncal vagotomy with short loop posterior gastrojejunostomy was done in 12 patients.

\section{Gastric Outlet Obstruction Due to Other Causes}

There was one patient with portahepatis lymph node enlargement secondary to renal cell carcinoma compressing the duodenum causing GOO and obstructive jaundice. Modified radical nephrectomy with portahepatis node excision done. 


\section{Comparison with Recent Studies}

\begin{tabular}{|c|c|c|c|c|}
\hline $\begin{array}{c}\text { Causes of } \\
\text { Gastric } \\
\text { outlet } \\
\text { obstruction }\end{array}$ & $\begin{array}{c}\text { SRM } \\
\text { Medical } \\
\text { College } \\
\text { Hospital } \\
\text { and } \\
\text { Research } \\
\text { Centre }\end{array}$ & $\begin{array}{c}\text { Shone } \\
\text { Nikoomesh } \\
\text { Smith et al. } \\
\text { in }\end{array}$ & $\begin{array}{c}\text { Mishra } \\
\text { Dwidedi } \\
\text { et al. }\end{array}$ & $\begin{array}{c}\text { Chowdry } \\
\text { G.K. } \\
\text { Dhali } \\
\text { Banerjee } \\
\text { et al. }\end{array}$ \\
\hline CA Antrum & $74 \%$ & $61 \%$ & $76 \%$ & $78 \%$ \\
\hline Chronic DU & $24 \%$ & $30 \%$ & $20 \%$ & $16 \%$ \\
\hline
\end{tabular}

\section{Postoperative Period}

In the post-operative period of the patients who underwent truncal vagotomy with posterior gastrojejunostomy, two patients had wound infection. The majority of the patients who underwent subtotal gastrectomy with Billroth type II anastomosis and anterior gastrojejunostomy had uneventful.

\section{COMPLICATIONS}

1. Three patients had wound infection.

2. One patient had obstruction at JJ anastomosis site.

The patients were discharged and advised to come for chemotherapy.

\section{CONCLUSION}

From this study of 50 adult cases, 37 cases were due to malignancy of the antrum of stomach, i.e. $74 \%$ and 12 cases were due to cicatrized duodenal ulcer, i.e. $24 \%$.

So with the advent of recent anti-ulcer drugs cicatrized duodenal ulcer decreased.(5) So the commonest cause of gastric outlet obstruction is cancer antrum of stomach, which has compared well with the recent studies.(6)

In carcinoma of antrum with gastric outlet obstruction males are 25 in number, i.e. 68\% and females are 12 in numbers, i.e. $32 \%$. In chronic duodenal ulcer with gastric outlet obstruction males are 8 in number i.e. $67 \%$ and females of 4 in numbers i.e. $33 \%$.
Commonest age group for cancer antrum with gastric outlet obstruction is 51-60 years and that of chronic DU with gastric outlet obstruction is 41-50 years.(7)

Oesophagogastroduodenoscopy (OGD) is a valuable tool in diagnosing all the causes.

Although proximal gastric carcinoma in on rise carcinoma stomach due to pyloric antral growth remains a leading cause of gastric outlet obstruction.(8)

In our hospital the first two common causes of gastric outlet obstruction and surgery is as follows:

For carcinoma of antrum - Subtotal gastrectomy

+ Billroth II gastrojejunostomy

For chronic duodenal ulcer -Truncal vagotomy

+posterior gastrojejunostomy

\section{REFERENCES}

1. Samad A, Whanzada TW, Shoukat I: Gastric outlet obstruction: change in etiology. Pak J Surg 2007;23:29-320.

2. Mishra SP, Dwivedi M, Misra V. Malignancy is the most common causes of gastric outlet obstruction even in a developing country. Endoscope J 30(5):484-6, 1998.

3. Endoscopic ultrasonography of the GIT Gastroenterology clinics of North America, 124, vol. 21995.

4. Sui WT, Tang CN, Law BKB, et al. (2004). Vagotomy and gastrojejunostomy for benign gastric outlet obstruction. J Laparoendosc Adv Surg Tech A 14:266-269.

5. Gibson JB, Behrman SW, Fabian TC, et al. Gastric outlet obstruction resulting from peptic ulcer disease requiring surgical intervention is infrequently associated with Helicobacter pylori infection. J Am Coll Surg 2000;191:32.

6. Johnson CD. Gastric outlet obstruction malignant until proved otherwise. Am J Gastroenterol 1995;90:1740.

7. Kreel L, Ellis H. Pyloric stenosis in adults: a clinical and radiological study of 100 consecutive patients. Gut 1965;6:253.

8. Shone DN, Nikoomanesh P, Smith-Meek MM, et al. Malignancy is the most common cause of gastric outlet obstruction in the era of $\mathrm{H} 2$ blockers. Am J Gastroenterol 1995;90:1769. 